\title{
Effect of common and experimental anti-tuberculosis treatments on Mycobacterium tuberculosis growing as biofilms
}

James P Dalton ${ }^{1,2,3}$, Benedict Uy ${ }^{1,2}$, Narisa Phummarin ${ }^{4}$, Brent R Copp ${ }^{3,4}$, William A Denny ${ }^{3,5}$, Simon Swift 1 , Siouxsie Wiles ${ }^{\text {Corresp. } 1,2,3}$

1 Molecular Medicine and Pathology, University of Auckland, Auckland, New Zealand

2 Bioluminescent Superbugs Lab, University of Auckland, Auckland, New Zealand

3 Maurice Wilkins Centre for Molecular Biodiscovery, Auckland, New Zealand

4 School of Chemical Sciences, University of Auckland, Auckland, New Zealand

5 Auckland Cancer Society Research Centre, University of Auckland, Auckland, New Zealand

Corresponding Author: Siouxsie Wiles

Email address: s.wiles@auckland.ac.nz

Much is known regarding the antibiotic susceptibility of planktonic cultures of Mycobacterium tuberculosis, the bacterium responsible for the lung disease tuberculosis (TB). As planktonically-grown M. tuberculosis are unlikely to be entirely representative of the bacterium during infection, we set out to determine how effective a range of antimycobacterial treatments were against $M$. tuberculosis growing as a biofilm, a bacterial phenotype known to be more resistant to antibiotic treatment. Light levels from bioluminescently-labelled M. tuberculosis H37Rv (strain BSG001) were used as a surrogate for bacterial viability, and were monitored before and after 1 week of treatment. After treatment, biofilms were disrupted, washed and inoculated into fresh broth and plated onto solid media to rescue any surviving bacteria. We found that in this phenotypic state $M$. tuberculosis was resistant to the majority of the compounds tested. Minimum inhibitory concentrations (MICs) increased by 20-fold to greater than 1000-fold, underlying the potential of this phenotype to cause significant problems during treatment. 
1

2

3

4

5

$6{ }^{1}$ Bioluminescent Superbugs Lab, University of Auckland, Auckland, New Zealand; ${ }^{2}$ Department of

7 Molecular Medicine and Pathology, University of Auckland, Auckland, New Zealand; ${ }^{3}$ Maurice Wilkins

8 Centre for Molecular Biodiscovery, New Zealand; ${ }^{4}$ School of Chemical Sciences, University of Auckland,

9 Auckland, New Zealand; ${ }^{5}$ Auckland Cancer Society Research Centre, University of Auckland, Auckland,

10 New Zealand.

11

12

13

14

15

16

17

18

19

20

21

22

23

24

25

Effect of common and experimental anti-tuberculosis treatments on Mycobacterium tuberculosis growing as biofilms

J.P. Dalton ${ }^{1,2,3}$, B. Uy $y^{1,2}$, N. Phummarin ${ }^{4}$, B. R. Copp ${ }^{3,4}$, W.A. Denny ${ }^{3,5}$, S. Swift ${ }^{2}$ and S. Wiles ${ }^{1,2,3^{*}}$

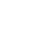

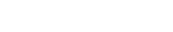

*Corresponding author: Dr. Siouxsie Wiles

Mailing address:

Dept. Molecular Medicine and Pathology,

University of Auckland,

Private Bag 92019,

Auckland,

New Zealand.

Tel: +64 93737599 Extension 84284,

Fax: +64 93738784 ,

E-mail: s.wiles@auckland.ac.nz

23

Keywords: Tuberculosis; TB; biofilm; pellicle; bioluminescence 


\section{Abstract}

Much is known regarding the antibiotic susceptibility of planktonic cultures of Mycobacterium tuberculosis, the bacterium responsible for the lung disease tuberculosis (TB). As planktonically-grown M. tuberculosis are unlikely to be entirely representative of the bacterium during infection, we set out to determine how effective a range of anti-mycobacterial treatments were against $M$. tuberculosis growing as a biofilm, a bacterial phenotype known to be more resistant to antibiotic treatment. Light levels from bioluminescently-labelled M. tuberculosis H37Rv (strain BSG001) were used as a surrogate for bacterial viability, and were monitored before and after 1 week of treatment. After treatment, biofilms were disrupted, washed and inoculated into fresh broth and plated onto solid media to rescue any surviving bacteria. We found that in this phenotypic state M. tuberculosis was resistant to the majority of the compounds tested. Minimum inhibitory concentrations (MICs) increased by 20 -fold to greater than 1000-fold, underlying the potential of this phenotype to cause significant problems during treatment.

\section{Introduction}

The bacterium Mycobacterium tuberculosis is responsible for the lung disease tuberculosis (TB). It is estimated that one third of the world's population is infected with this deadly pathogen. ${ }^{1}$ While TB represents a huge burden on health care systems in its own right, it also complicates other serious illnesses such as HIV/AIDS. ${ }^{1}$ New compounds are desperately required to shorten the current TB treatment regimes, which routinely last longer than 6 months, and to combat the rise of resistant $M$. tuberculosis strains. Drug-resistant TB leads to extended hospital stays and treatment times and, in the worst case scenario, untreatable disease. ${ }^{2,3}$

Bacterial cells present in an infected host can display a range of phenotypes and occupy several divergent physiological niches. ${ }^{4,5}$ For example, during infection, cells of $M$. tuberculosis can be both replicative and non-replicative ${ }^{6}$ and occupy a number of different niches, including macrophages ${ }^{7}$ and necrotic and nonnecrotic lesions. ${ }^{8} M$. tuberculosis growing in such diverse environments is unlikely to be accurately reflected by planktonically-grown laboratory cultures. Many bacteria can form microcolonies called biofilms, which can contain a mixture of replicating and non-replicating cells, and cells in different metabolic states. ${ }^{9,} 10$ Bacteria can form biofilms at the interface between a surface and the surrounding air or liquid. Alternatively, floating biofilms can form at a liquid/air interface. These floating biofilms are also known as pellicles. Within a biofilm or pellicle, bacterial cells are more resistant to disinfection and 
drug treatment and therefore represent a much harder target to sterilise. ${ }^{11,12}$ As such, the biofilm/pellicle represents a useful model for investigating the efficacy of antibacterial treatments.

M. tuberculosis can form pellicles in vitro ${ }^{13}$ and the presence of microcolonies of extracellular $M$. tuberculosis in animal models has led to speculation that these are biofilms formed in vivo. ${ }^{14}$ Some sources point to the possible presence of pellicles in the lung-air interface present in secondary TB in humans; ${ }^{15-}$ 17 and indicate that the susceptibility of this phenotype to antibacterial compounds is of particular relevance from a treatment standpoint. Here we describe the use of bioluminescently-tagged $M$. tuberculosis to investigate the susceptibility of pellicle cells to a range of anti-mycobacterial compounds, including those in current clinical use as well as a selection of experimental compounds.

\section{Materials and methods}

\section{Strains and growth conditions}

In this study we used M. tuberculosis BSG001 ${ }^{18}$, a stable bioluminescent derivative of H37Rv transformed with the integrating plasmid pMV306hspLuXABG13CDE. ${ }^{19}$ Cultures of BSG001 were grown at $37^{\circ} \mathrm{C}$ with gentle shaking (100rpm) in Middlebrook 7H9 broth (Fort Richard, Auckland) supplemented with 10\% Middlebrook ADC enrichment media (Fort Richard) and 0.5\% glycerol (Sigma-Aldrich), or on 7H11 agar (Fort Richard) supplemented with 10\% Middlebrook OADC enrichment media (Fort Richard) and $0.5 \%$ glycerol. We grew pellicles in sterile, black 96 well plates (Nunc) using a previously described method. ${ }^{11}$ Briefly, we grew M. tuberculosis BSG001 in liquid culture for 2 weeks at $37^{\circ} \mathrm{C}$ and then adjusted the cultures to give an optical density at $600 \mathrm{~nm}\left(\mathrm{OD}_{600}\right)$ of 1.0 , before diluting them 1:100 in modified Sauton's media $\left(0.5 \mathrm{~g} / \mathrm{L} \mathrm{KH}_{2} \mathrm{PO}_{4}, 0.5 \mathrm{~g} / \mathrm{L} \mathrm{MgSO}_{4}, 4 \mathrm{~g} / \mathrm{L} \mathrm{L}\right.$-Asparagine, $2 \mathrm{~g} / \mathrm{L}$ Citric acid, $0.05 \mathrm{~g} / \mathrm{L}$ Ferric Ammonium Citrate, $60 \mathrm{~mL} / \mathrm{L}$ glycerol, $0.1 \% \mathrm{ZnSO}_{4}, \mathrm{pH} 7.0$ [all chemicals from Sigma-Aldrich]) and adding $100 \mu \mathrm{L}$ aliquots to each inner well of a 96 well plate. We filled the outer wells with $200 \mu \mathrm{L}$ of sterile water to reduce evaporation from the M. tuberculosis containing wells. We incubated the cultures without shaking for 8 weeks at $37^{\circ} \mathrm{C}$.

\section{Determination of compound activity}

Once pellicles had established, we determined how much media remained in the wells by removing all liquid from 12 non-tested wells and taking an average volume. This is necessary as some evaporation occurs because of the long incubation time, and this has to be accounted for when calculating final 
compound concentrations. Similar levels of liquid were lost from all wells tested. We added test compounds (Table 1 \& Fig. 1, all supplied by Sigma Aldrich with the exception of the nitroimidazole and 2-(quinoline-4-yloxy) acetamide-based compounds) dissolved in Sauton's media to the M. tuberculosis pellicles in a two-fold dilution gradient at a range of concentrations. Concentrations of each compound were chosen based on the minimum inhibitory concentrations (MIC) for planktonically-grown $M$. tuberculosis BSG001, which vary greatly between the compounds tested. We tested up to 1000 -fold the planktonic MIC concentration, depending on the solubility of the test compound. Each concentration was done in duplicate, using three independent BSG001 cultures. Biofilms were incubated for a further 7 days at $37^{\circ} \mathrm{C}$ with no shaking and light levels (given as Relative Light Units [RLU]) were measured before and after treatment using a Victor X-3 luminometer (Perkin Elmer). We have defined the MIC as causing a 1 log reduction in light production, as previously described. ${ }^{20}$

To determine the minimum bactericidal concentration (MBC), pellicles were removed from the wells, disrupted by pipetting and washed 3 times in Sauton's media supplemented with $0.05 \%$ tween 80 . The cells were then resuspended in fresh $7 \mathrm{H} 9$ broth $(5 \mathrm{ml}$, supplemented as described above) and plated onto $7 \mathrm{H} 11$ agar (supplemented as described above). We have defined the MBC as the concentration which resulted in no growth. We incubated broth cultures for 2 weeks and plate cultures for 8 weeks to recover any surviving bacteria. All experiments were performed using three biological replicates of $M$. tuberculosis BSG001 and two technical replicates. Biological replicates were grown separately and tested on different days.

\section{Results}

\section{Decreased susceptibility of pellicle-grown $M$. tuberculosis to front-line and experimental compounds.}

Of the four main first line drugs only rifampicin was seen to inhibit pellicles of $M$. tuberculosis at the concentrations tested (Table 1, Fig. 2B, Fig. 3B). Isoniazid also led to some inhibition but below the threshold defined (Fig. 2C, Fig. 3C). In the case of rifampicin the MIC and MBC for pellicle-grown BSG001 were determined to be $4 \mathrm{mg} / \mathrm{L}, 100$ times the concentration required to produce a similar result with planktonic cells (Table 1). High levels of pyrazinamide, isoniazid and ethambutol (20, 6000 and 1000 times the MIC's for planktonic cells, respectively) failed to sufficiently reduce light to be classed as inhibitory (Table 1, Fig. 2A-D, Fig. 3A-D). More success was observed with non-first line antibiotics, with MICs obtained for pellicle-grown BSG001 for streptomycin (125 mg/L), amikacin ( $250 \mathrm{mg} / \mathrm{L}$ ) and 
114 rifabutin (8 mg/L) (Table 1, Fig. 2E-G, Fig. 3E-G). These pellicle-MICs represent an increase of 250, 62.5

115 and 200 times the MIC's obtained for planktonic cultures, respectively (Table 1).

116 When novel and experimental compounds were examined, none of the current derivations of the 117 nitroimidazole based compounds ${ }^{21,22}$ (delamanid, pretomanid and SN30488) were able to reduce light 118 from the pellicle-grown M. tuberculosis at the concentrations tested (Table 1, Fig.2H-J, Fig.3H-J). The same resistance to drug-killing was seen with experimental compounds based on 2-(quinoline-4-yloxy) acetamides $^{23}$ (QOA 1, QOA 2 and QOA 3)(Table 1, Fig. 2K-M, Fig.3K-M). In contrast, the fluoroanthranilicacid based compounds, 5-fluoroanthranilic acid (5-FAA) and 6-fluoroanthranilic acid (6-FAA), which target the tryptophan biosynthetic pathway ${ }^{24}$ were seen to be quite effective at inhibiting light from $M$. tuberculosis BCG001 growing as a pellicles (Table 1, Fig.2N/O, Fig.3N/O). Ascorbic acid was also seen to cause inhibition at $2.8 \mathrm{~g} / \mathrm{L}, 4$ times the MIC for planktonically-grown M. tuberculosis (Table 1, Fig. 2P,

125 Fig.3P).

Discussion

Many infectious bacteria form biofilms within their host. Bacteria living within a biofilm are notoriously difficult to treat and can persist for extended periods of time, as they have the ability to resist the immune system, ${ }^{25}$ display increased virulence ${ }^{26,27}$ and can become phenotypically more resistant to antibiotics. It is common for antibiotic concentrations required to control bacteria within biofilms to be 100 to 1000 fold greater than those needed to treat planktonic forms. ${ }^{12}$ This was seen to be true of the majority of compounds tested in this study. In many cases this is not too surprising. Biofilms can affect drug activity by acting as a physical barrier to entry into the cell. The phenotypic state of the cells within the biofilm could also make the cells less susceptible. Isoniazid's mode of action relates to mycolic acid synthesis. When growing as a pellicle, it is possible that mycolic acid synthesis is minimal or nonessential. Similarly ethambutol, delamanid and pretomanid are also thought to affect various steps in cell wall biosynthesis and formation; none of these were seen to have an effect. Pyrazinamide relies on conversion to pyrazinoic acid, which requires acidic conditions to become active. This could indicate that these conditions are not present in mycobacterial pellicles or that the drug is unable to penetrate the cells in this phenotype. If it is due to the lack of an acidic environment this could represent a limitation in using this model for drug testing. In contrast, antibiotics that affect protein synthesis, such as rifampicin, rifabutin, amikacin and streptomycin, displayed some degree of inhibitive activity towards 
144 pellicle-grown M. tuberculosis, although this activity was lower than the activity against planktonically-

145 grown cells. The 2-(quinoline-4-yloxy) acetamide based compounds also showed little activity against

146 this biofilm form. The mode of action of these compounds is likely due to electron transport inhibition of

147 cytochrome bc1 oxidase. ${ }^{23}$ As the cells are actively metabolising, the lack of an effect from these

148 compounds is most likely due to an inability to access the cells.

149 In our study, we observed that M. tuberculosis growing as a pellicle is susceptible to a concentration of

150 ascorbic acid similar to that reported for planktonically-grown cells. This concentration was also

151 sufficient to cause death of the M. tuberculosis pellicle within 1 week of treatment. The activity of

152 ascorbic acid is thought to be due to the generation of highly reactive hydroxyl radicals via presence of

153 iron and Fenton reaction chemistry. ${ }^{28}$ Killing due to this mechanism would be non-specific and not

154 dependant on uptake. Interestingly the fluoroanthranilic acid tryptophan biosynthesis inhibitors were

155 also seen to be effective at inhibiting and killing pellicles, indicating that this is a pathway worthy of

156 further consideration for drug targeting.

157 It is possible that the comparative ease in which test compounds can access bacteria within a pellicle,

158 that is from both above and below, as compared to a biofilm attached to a surface which cannot be

159 accessed from the surface side, make this form of biofilm easier to kill. While it is still unknown if $M$.

160 tuberculosis forms biofilms/pellicles in vivo, many mycobacterial species do form complex, secondary

161 structures such as pellicles in vitro. ${ }^{29}$ Researchers have also reported histological evidence for the

162 presence of multicellular structures involving $M$. tuberculosis outside of the macrophage. ${ }^{30}$ Others have

163 reported the presence of cells that resembles biofilms/pellicles in the cavities formed during secondary

164 tuberculosis which would indicate that this phenotype is likely to play a role in human disease. ${ }^{14,15,17}$

165 The biphasic response of M. tuberculosis infections, in which a large kill is seen early on in drug

166 treatment followed by a marked reduction in the bactericidal activity of therapeutic agents due to

167 phenotypic rather than genetic resistance, could also be evidence that $M$. tuberculosis is able to form

168 biofilms/pellicles in vivo. Such structures could act as a reservoir for drug tolerant bacilli which are

169 responsible for the increased duration of drug treatment required in cases of TB. Regardless, the $M$.

170 tuberculosis-pellicle model is a useful multi-phenotypic environment in which a novel compound can be

171 tested against cells with a range of susceptibilities. The susceptibility of $M$. tuberculosis within this

172 model indicates that drugs which can attack the surface of the cell or can pass through the extracellular

173 matrix of the pellicle represent the best option for treatment. We also saw that the inhibition of 
174 tryptophan biosynthesis could be utilised in TB treatment and their design should be further

175 investigated.

\section{Funding}

178

This work was supported by the Maurice Wilkins Centre for Molecular Biodiscovery and the University of Auckland Vice-Chancellor's Strategic Development Fund and Faculty Research Development Fund. SW was supported by a Sir Charles Hercus Fellowship (09/099) from the Health Research Council of New Zealand.

\section{References}

1. WHO. Global tuberculosis report 2015. Geneva, Switzerland, 2015.

2. Klopper M, Warren RM, Hayes $\mathrm{C}$ et al. Emergence and spread of extensively and totally drugresistant tuberculosis, South Africa. Emerg Infect Dis 2013; 19: 449-55.

3. WHO. World Health Organization. Guidelines for the programmatic management of drugresistant tuberculosis - 2011 update

Geneva, Switzerland:, 2011.

4. Sendi P, Johansson L, Dahesh S et al. Bacterial phenotype variants in group B streptococcal toxic shock syndrome. Emerg Infect Dis 2009; 15: 223-32.

5. Tuchscherr L, Medina E, Hussain M et al. Staphylococcus aureus phenotype switching: an effective bacterial strategy to escape host immune response and establish a chronic infection. $E M B O$ Mol Med 2011; 3: 129-41.

6. Wayne LG, Sohaskey CD. Nonreplicating persistence of mycobacterium tuberculosis. Annu Rev Microbiol 2001; 55: 139-63.

7. Rengarajan J, Bloom BR, Rubin EJ. Genome-wide requirements for Mycobacterium tuberculosis adaptation and survival in macrophages. Proc Natl Acad Sci U S A 2005; 102: 8327-32.

8. Fenhalls $G$, Stevens L, Moses L et al. In situ detection of Mycobacterium tuberculosis transcripts in human lung granulomas reveals differential gene expression in necrotic lesions. Infect Immun 2002; 70: 6330-8.

9. Rice AR, Hamilton MA, Camper AK. Movement, Replication, and Emigration Rates of Individual Bacteria in a Biofilm. Microb Ecol 2003; 45: 163-72.

10. Stewart PS, Franklin MJ. Physiological heterogeneity in biofilms. Nat Rev Micro 2008; 6: 199-210.

11. Kulka K, Hatfull G, Ojha AK. Growth of Mycobacterium tuberculosis biofilms. J Vis Exp 2012.

12. Ceri $\mathrm{H}$, Olson $\mathrm{ME}$, Stremick $\mathrm{C}$ et al. The Calgary Biofilm Device: new technology for rapid determination of antibiotic susceptibilities of bacterial biofilms. J Clin Microbiol 1999; 37: 1771-6.

13. Sambandan D, Dao DN, Weinrick BC et al. Keto-mycolic acid-dependent pellicle formation confers tolerance to drug-sensitive Mycobacterium tuberculosis. MBio 2013; 4: e00222-13.

14. Lenaerts AJ, Hoff D Fau - Aly S, Aly S Fau - Ehlers S et al. Location of persisting mycobacteria in a Guinea pig model of tuberculosis revealed by r207910. 2007. 
212 15. Hunter RL, Olsen MR, Jagannath C et al. Multiple roles of cord factor in the pathogenesis of 213 primary, secondary, and cavitary tuberculosis, including a revised description of the pathology of 214 secondary disease. Ann Clin Lab Sci 2006; 36: 371-86.

215 16. Hunter RL, Armitige L, Jagannath C et al. TB Research at UT-Houston; A review of cord factor: 216 new approaches to drugs, vaccines and the pathogenesis of tuberculosis. Tuberculosis 2013; 89: S18-

217 S25.

218 17. Hunter RL, Actor JK, Hwang SA et al. Pathogenesis of post primary tuberculosis: immunity and hypersensitivity in the development of cavities. Ann Clin Lab Sci 2014; 44: 365-87. Hydroxylated 1,2,3,4-Tetrahydro-beta-carboline Constituents of the New Zealand Ascidian Pseudodistoma opacum. J Nat Prod 2016; 79: 607-10.

19. Andreu N, Zelmer A, Fletcher T et al. Optimisation of bioluminescent reporters for use with mycobacteria. PLoS One 2010; 5: e10777.

20. Andreu $\mathrm{N}$, Fletcher $\mathrm{T}$, Krishnan $\mathrm{N}$ et al. Rapid measurement of antituberculosis drug activity in vitro and in macrophages using bioluminescence. J Antimicrob Chemother 2012; 67: 404-14.

21. Olaru ID, von Groote-Bidlingmaier F, Heyckendorf J et al. Novel drugs against tuberculosis: a clinician's perspective. Eur Respir J 2015; 45: 1119-31.

22. Palmer BD, Thompson AM, Sutherland HS et al. Synthesis and structure-activity studies of biphenyl analogues of the tuberculosis drug (6S)-2-nitro-6-\{[4-(trifluoromethoxy)benzyl]oxy\}-6,7dihydro-5H-imidazo[2,1-b][1, 3]oxazine (PA-824). J Med Chem 2010; 53: 282-94.

23. Phummarin N, Boshoff HI, Tsang PS et al. SAR and identification of 2-(quinolin-4yloxy)acetamides as Mycobacterium tuberculosis cytochrome bc1 inhibitors. MedChemComm 2016.

24. Toyn JH, Gunyuzlu PL, White WH et al. A counterselection for the tryptophan pathway in yeast: 5-fluoroanthranilic acid resistance. Yeast 2000; 16: 553-60.

25. Donlan RM, Costerton JW. Biofilms: survival mechanisms of clinically relevant microorganisms. Clin Microbiol Rev 2002; 15: 167-93.

26. Safadi RA, Abu-Ali GS, Sloup RE et al. Correlation between In Vivo Biofilm Formation and Virulence Gene Expression in Escherichia coli 0104:H4. PLoS One 2012; 7: e41628. mellonella following biofilm adaptation. Journal of Medical Microbiology 2012; 61: 470-7.

28. Vilcheze $C$, Hartman T, Weinrick B et al. Mycobacterium tuberculosis is extraordinarily sensitive to killing by a vitamin C-induced Fenton reaction. Nat Commun 2013; 4: 1881.

29. Ojha AK, Hatfull GF. Biofilms of Mycobacterium tuberculosis: New Perspectives of an Old Pathogen. In: Cardona DP-J, ed. Understanding Tuberculosis - Deciphering the Secret Life of the Bacilli: InTech, 2012.

30. Lenaerts AJ, Hoff D, Aly S et al. Location of persisting mycobacteria in a Guinea pig model of tuberculosis revealed by r207910. Antimicrob Agents Chemother 2007; 51: 3338-45. 


\begin{tabular}{ccccc}
\hline & Planktonic & Biofilm & Planktonic & Biofilm \\
& MIC & MIC & MBC & MBC $^{2}$ \\
\hline Pyrazinamide & $50 \mathrm{mg} / \mathrm{L}$ & $>1000 \mathrm{mg} / \mathrm{L}$ & $50 \mathrm{mg} / \mathrm{L}$ & $>1000 \mathrm{mg} / \mathrm{L}$ \\
Rifampicin & $0.04 \mathrm{mg} / \mathrm{L}$ & $4 \mathrm{mg} / \mathrm{L}$ & $0.04 \mathrm{mg} / \mathrm{L}$ & $4 \mathrm{mg} / \mathrm{L}$ \\
Isoniazid & $0.04 \mathrm{mg} / \mathrm{L}$ & $>256 \mathrm{mg} / \mathrm{L}$ & $0.08 \mathrm{mg} / \mathrm{L}$ & $>256 \mathrm{mg} / \mathrm{L}$ \\
Ethambutol & $1 \mathrm{mg} / \mathrm{L}$ & $>2000 \mathrm{mg} / \mathrm{L}$ & $2 \mathrm{mg} / \mathrm{L}$ & $>2000 \mathrm{mg} / \mathrm{L}$ \\
Streptomycin & $0.5 \mathrm{mg} / \mathrm{L}$ & $125 \mathrm{mg} / \mathrm{L}$ & $0.5 \mathrm{mg} / \mathrm{L}$ & $1000 \mathrm{mg} / \mathrm{L}$ \\
Amikacin & $4 \mathrm{mg} / \mathrm{L}$ & $250 \mathrm{mg} / \mathrm{L}$ & $4 \mathrm{mg} / \mathrm{L}$ & $1000 \mathrm{mg} / \mathrm{L}$ \\
Rifabutin & $0.04 \mathrm{mg} / \mathrm{L}$ & $8 \mathrm{mg} / \mathrm{L}$ & $0.04 \mathrm{mg} / \mathrm{L}$ & $16 \mathrm{mg} / \mathrm{L}$ \\
Ascorbic acid & $700 \mathrm{mg} / \mathrm{L}$ & $2800 \mathrm{mg} / \mathrm{L}$ & $700 \mathrm{mg} / \mathrm{L}$ & $2800 \mathrm{mg} / \mathrm{L}$ \\
Delamanid & $0.042 \mathrm{mg} / \mathrm{L}$ & $>53.45 \mathrm{mg} / \mathrm{L}$ & $0.042 \mathrm{mg} / \mathrm{L}$ & $>53.45 \mathrm{mg} / \mathrm{L}$ \\
Pretomanid & $0.011 \mathrm{mg} / \mathrm{L}$ & $>3.6 \mathrm{mg} / \mathrm{L}$ & $0.011 \mathrm{mg} / \mathrm{L}$ & $>3.6 \mathrm{mg} / \mathrm{L}$ \\
SN30488 & $0.0056 \mathrm{mg} / \mathrm{L}$ & $>4.2 \mathrm{mg} / \mathrm{L}$ & $0.0056 \mathrm{mg} / \mathrm{L}$ & $>4.2 \mathrm{mg} / \mathrm{L}$ \\
QOA1 & $0.5 \mathrm{mg} / \mathrm{L}$ & $>128 \mathrm{mg} / \mathrm{L}$ & $0.5 \mathrm{mg} / \mathrm{L}$ & $>128 \mathrm{mg} / \mathrm{L}$ \\
QOA2 & $0.25 \mathrm{mg} / \mathrm{L}$ & $>128 \mathrm{mg} / \mathrm{L}$ & $0.25 \mathrm{mg} / \mathrm{L}$ & $>128 \mathrm{mg} / \mathrm{L}$ \\
QOA3 & $0.25 \mathrm{mg} / \mathrm{L}$ & $>128 \mathrm{mg} / \mathrm{L}$ & $0.25 \mathrm{mg} / \mathrm{L}$ & $>128 \mathrm{mg} / \mathrm{L}$ \\
5-FAA & $9.7 \mathrm{mg} / \mathrm{L}$ & $19.4 \mathrm{mg} / \mathrm{L}$ & $19.4 \mathrm{mg} / \mathrm{L}$ & $19.4 \mathrm{mg} / \mathrm{L}$ \\
6-FAA & $9.7 \mathrm{mg} / \mathrm{L}$ & $19.4 \mathrm{mg} / \mathrm{L}$ & $19.4 \mathrm{mg} / \mathrm{L}$ & $19.4 \mathrm{mg} / \mathrm{L}$
\end{tabular}

252 Table 1: ${ }^{1}$ Minimum inhibitory concentrations (MIC) and ${ }^{2}$ minimum bactericidal concentrations (MBC) for

253 biofilm and planktonic forms of M. tuberculosis BSG001 for a variety of experimental and non-

254 experimental compounds. ${ }^{3}$ fluoroanthranilic acid. 
257 Figure 1. Chemical structures of the experimental compounds used in this study.

258

259

260

261

262

263

264

265

266

267

268

269

270

271

272

273

274

275

276

277

278

279

280

281

Figure 2. The effect of clinically-used and experimental compounds on M. tuberculosis BSG001

pellicles. The inhibitory effect of first line (A-D) and second line (E-G) anti-tuberculosis drugs used in the clinic and experimental compounds (H-P), including those based on nitroimidazole $(\mathrm{H}-\mathrm{J}),(2-$ (quinoline-4yloxy) acetamides (K-M) and fluoroanthranilic-acid $(\mathrm{N}, \mathrm{O})$, is presented as a reduction in bioluminescence plotted as relative light units (RLU) per well on day 7 of treatment. The dashed line indicates the limit of detection. The solid and open arrows indicate the MBC's (the concentration which resulted in the recovery of no bacterial colonies) obtained for planktonically-grown cells and pellicles, respectively. All compounds were tested in three biological replicates on separate days with multiple technical replicates. Results are given as box whisker plots with the box representing values from the lower to upper quartile and the whiskers representing the range.

Figure 3. The relative effect of clinically-used and experimental compounds on $M$. tuberculosis BSG001 pellicles. The relative change in bioluminescence (relative light units [RLU]) following the treatment of M. tuberculosis BSG001 biofilms with first line (A-D) and second line (E-G) anti-tuberculosis drugs used in the clinic and experimental compounds $(\mathrm{H}-\mathrm{P})$, including those based on nitroimidazole $(\mathrm{H}-\mathrm{J}),(2-$ (quinoline-4-yloxy) acetamides (K-M) and fluoroanthranilic-acid $(\mathrm{N}, \mathrm{O})$, is shown as the ratio of RLU before treatment and RLU after 7 days of treatment. The dashed line indicates the level at which no change occurs; values above the dashed line indicate an increase in light levels (and hence survival/growth) over the course of the experiment, while those below indicate a decrease (and hence inhibition/death). The solid and open arrows indicate the MBC's (the concentration which resulted in the recovery of no bacterial colonies) obtained for planktonically-grown cells and pellicles, respectively. Results are given as box whisker plots with the box representing values from the lower to upper quartile and the whiskers representing the range. 
282 Figure 1<smiles>O=[N+]([O-])c1cn2c(n1)OC[C@@H](OCc1ccc(OC(F)(F)F)cc1)C2</smiles><smiles>CC(F)(F)Oc1ccc(OC2CCN(c3ccc(OC[C@@]4(C)Cn5cc([N+](=O)[O-])nc5O4)cc3)CC2)cc1</smiles><smiles>COc1ccc2nc(C)cc(OCC(=O)Nc3ccccc3OC)c2c1</smiles><smiles>COc1ccc2nc(C)cc(OCC(=O)Nc3ccc(C)cc3)c2c1OCC(=O)NCc1ccc2c(c1)OCO2</smiles><smiles>Nc1ccc(F)cc1C(=O)O</smiles><smiles>Nc1cccc(F)c1C(=O)O</smiles> 
Figure 2
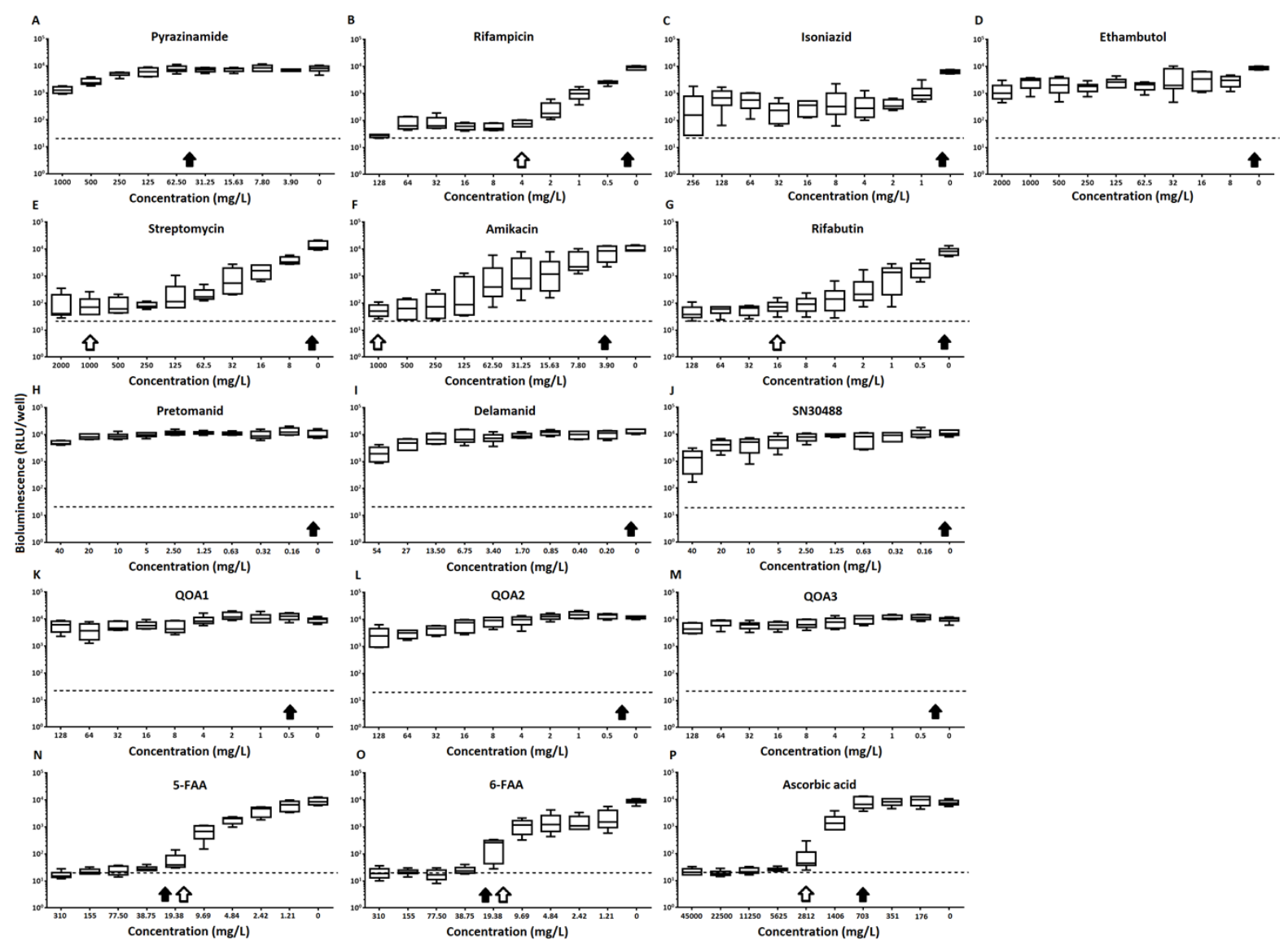

287 


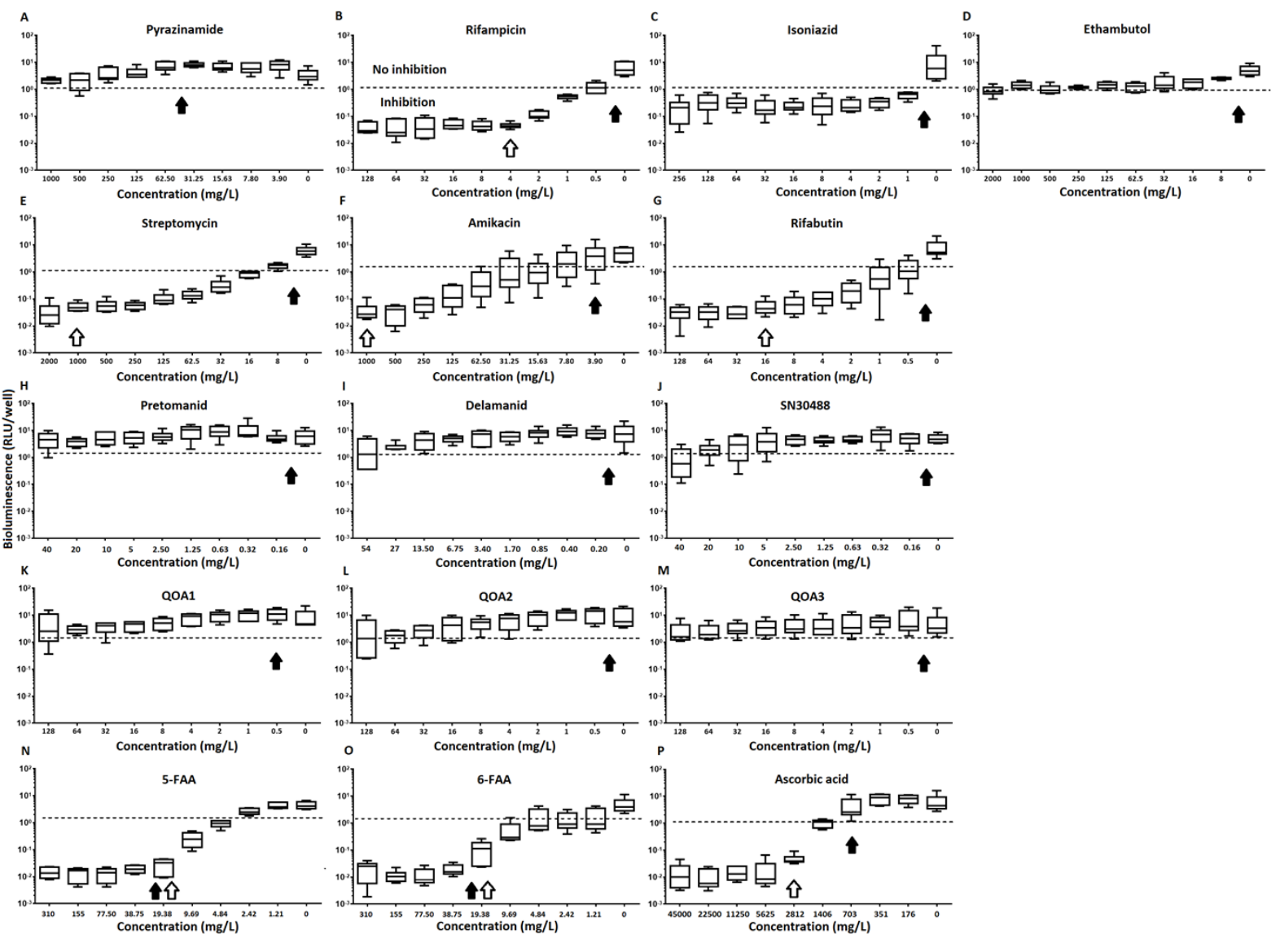

